\title{
Risk of coronary artery involvement in Kawasaki disease
}

\author{
María Soriano-Ramos, B.S. ${ }^{a}$, Elena Martínez-del Val, Magister ${ }^{a}$, \\ Sagrario Negreira Cepeda, M.D. ${ }^{a}$, María I. González-Tomé, M.D. ${ }^{a}$, \\ Pilar Cedena Romero, B.S. ${ }^{a}$, Elisa Fernández-Cooke, M.D. ${ }^{a}$, Leticia Albert de la Torre, B.S. ${ }^{a}$ \\ and Daniel Blázquez-Gamero, B.S. ${ }^{a}$
}

\begin{abstract}
Introduction:Kawasakidisease refers to systemic vasculitis with risk of coronary artery disease. Our objective is to identify risk factors associated with coronary artery disease in patients with complete and incomplete Kawasaki disease. Material and methods: Descriptive, retrospective study conducted in patients diagnosed with Kawasaki disease in a tertiary-care hospital between 2008 and 2014. The American Heart Association diagnostic criteria were used to define complete and incomplete Kawasaki disease.

Results: Thirty-one children were diagnosed with Kawasaki disease; 24 met the criteria for the complete form, and 7, for the incomplete form of this condition. Five had coronary artery disease. One of them had incomplete Kawasaki disease $(1 / 7=14.3 \%)$, and the remaining four had the complete form $(4 / 24=16.7 \%)$. No significant differences were found between both groups $(p=1.0)$. Patients with coronary artery involvement had a higher C-reactive protein level (median: $16.2 \mathrm{mg} / \mathrm{dL}$ versus $8.4 \mathrm{mg} / \mathrm{dL}$, $p=0.047$ ) and lower albuminemia (median: $3.2 \mathrm{mg} / \mathrm{dL}$ versus $3.99 \mathrm{mg} / \mathrm{dL}, p=0.002$ ).

Conclusions: The risk of coronary artery involvement in incomplete Kawasaki disease is similar to that in complete Kawasaki disease; therefore, in patients with the incomplete form, immunoglobulin therapy should not be delayed. In our population, C-reactive protein and albumin levels were related to a higher risk of coronary artery involvement.

Key words: Kawasaki disease, risk factors, coronary artery disease.
\end{abstract}

http:/ /dx.doi.org/10.5546/aap.2016.eng.107

\section{INTRODUCTION}

Kawasaki disease (KD), described

E-mail address:

María Soriano-Ramos, B.S.: sorianoramosmaria@ gmail.com.

Funding:

None.

Conflict of interest:

None

Received: 08-06-2015

Accepted: 10-16-2015
239.6/100 000 children younger than 5 years old, the distribution pattern of the disease is universal and can be found in children of any ethnic group. ${ }^{2}$ In the United States, KD has an overall hospitalization rate of $17.1 / 100$ 000 children. In Europe, some studies have established KD incidence to be between 4.9/100 000 children younger than 5 years old in Denmark and 9/100 000 children in France. ${ }^{2}$

The prognosis of the disease depends on the degree of coronary artery disease (CAD). Up to 15$25 \%$ of untreated patients have CAD. Such percentage decreases to less than $5 \%$ in patients receiving gammaglobulin treatment before day 10 of the disease. ${ }^{1,3}$ Currently, KD is considered the main cause of acquired heart disease during childhood in developed countries. ${ }^{3,4}$ Incomplete KD has been related to a greater delay in diagnosis and treatment onset, which, in turn, could result in a higher CAD risk. ${ }^{5,6}$

Our objective is to identify risk factors associated with coronary artery disease in patients with complete and incomplete KD.

\section{MATERIAL AND METHODS}

A retrospective, descriptive study has been performed in which medical records of children younger than 18 years old, diagnosed with KD, have been collected in a tertiary care hospital, between January 2008 and December 2014.

KD diagnosis in its complete and incomplete form was established according to the criteria defined by the American Heart Association (AHA). ${ }^{7}$ Complete KD diagnostic 
criteria were fever persisting at least 5 days and the presence of at least 4 of the following 5 criteria: (1) changes in limbs: erythema of the palms and soles or swelling of the hand and feet in the acute phase and/or fingers and toes periungual desquamation in the subacute phase; (2) polymorphous exanthema; (3) bilateral nonexudative conjunctival injection; (4) changes in lips and oral cavity: erythema and cracking of lips, strawberry tongue and pharyngeal hyperemia; (5) cervical lymph node enlargement $(>1.5 \mathrm{~cm}$ in diameter), excluding other diseases with similar clinical features. Incomplete KD diagnostic criteria were the following: ${ }^{7}$ fever of, at least, 5 days long and the presence of 2 or 3 of the previously mentioned clinical criteria of the disease, together with C-reactive protein (CRP) $\geq 3 \mathrm{mg} / \mathrm{dL}$ and/or erythrocyte sedimentation rate $(E S R) \geq 40 \mathrm{~mm} / \mathrm{h}$ and, at least, 3 of the following analytical abnormalities: albumin $\leq 3 \mathrm{~g} / \mathrm{dL}$, anemia for the age, increased level of the glutamic pyruvic transaminase (GPT), platelet level after day $7 \geq 450000 / \mathrm{mm}^{3}$, total leukocytes $\geq 15000 / \mathrm{mm}^{3}$ and pyuria $\geq 10$ leukocytes/high power field. The first day of the disease was defined as the first day with a body temperature $\geq 38^{\circ} \mathrm{C}$.

The standard treatment was that recommended by the American Academy of Pediatrics ${ }^{7}$ consensus that consists of the administration of an IV gammaglobulin dose $(2 \mathrm{~g} / \mathrm{kg})$ combined with acetylsalicylic acid (ASA) in anti-inflammatory doses $(80-100 \mathrm{mg} / \mathrm{kg})$ up to 48-72 hours after the fever had stopped and CRP levels had normalized, to continue with ASA in antiplatelet dose (3-5 mg/ $\mathrm{kg})$, at least during 2 weeks, and if there are coronary artery abnormalities, until they are no longer present.

An echocardiography was done within the first 48 hours after the diagnosis of complete or incomplete KD. According to the study group of $\mathrm{KD}$ of the $\mathrm{AHA},{ }^{7}$ the following grades of risk stratification were considered: (I) no coronary artery changes; (II) transient coronary artery ectasia or dilation that resolved in 6-8 weeks; (III) single aneurysm $>3 \mathrm{~mm}$, but $<6 \mathrm{~mm}$ in $\geq 1$ coronary artery; (IV) $\geq 1$ aneurysm $\geq 6 \mathrm{~mm}$ or multiple aneurysms in the same coronary artery; and $(\mathrm{V})$ coronary artery obstruction observed during angiography. Any dilation $\leq 3 \mathrm{~mm}$ with a $\mathrm{Z}$ score $>2$ was considered coronary ectasia.

The study database was developed using Microsoft Access 2010, and IBM SPSS Statistics 20.0 was used for the statistical analysis.

Quantitative outcome measures were described using the mean and standard deviation (SD), or the median and the interquartile range (IQR) based on the distribution of each outcome measure. Qualitative outcome measures were stated as counts (n) and percentages (\%). Quantitative outcome measures were compared by means of the Student's t test if outcome measure distribution met normality criteria, or by the Mann-Whitney test if the distribution was abnormal. Comparisons between the two qualitative outcome measures were done with the $\chi^{2}$ test. A $p<0.05$ was considered as the limit of statistical significance.

This study was conducted following the principles of good practices outlined in the Declaration of Helsinki. The hospital Ethics Committee approved the conduction of this study.

\section{RESULTS}

During the study period, 35 children were diagnosed with KD; 24 (77.4\%) met the criteria for the complete form, and 7 (22.6\%), for the incomplete form. Four children were excluded because they did not meet KD (complete or incomplete) diagnostic criteria or they had not been correctly identified in the medical records.

Overall characteristics of the 31 patients included, like gender and age at the time of the diagnosis, can be seen in Table 1. Ages of the 5 patients with CAD were 3.2, 5.6, 6.8, 12.1 and 58.3 months old. The median age of this group of patients was 6.8 months old (IQR: 4.4-35.2).

Of all cases, $32.2 \%$ occurred in winter; $25.8 \%$, in summer; $22.6 \%$, in spring; and $19.3 \%$, in autumn. The median number of visits to the Emergency Department prior to the diagnosis was 1.00 (IQR: 1-3). Eighteen (58.1\%) patients had received antibiotic treatment prior to KD diagnosis due to suspected bacterial disease.

\section{Clinical manifestations and laboratory findings}

Clinical manifestations that patients had at the time of KD diagnosis are described in Table 1. Together with KD diagnostic criteria, it is worth pointing out that 3 patients had liver enlargement and 1, gallbladder hydrops. Irritability was especially present in younger patients. In short, $75 \%$ of children under 2 years old, and $100 \%$ of those under 1 year old had this symptom as a characteristic finding. Sterile pyuria was detected in 9 cases (29\%). Regarding the main clinical differences between incomplete and complete KD, we have found that in the 7 
patients with incomplete $\mathrm{KD}$, the most common findings were periungual desquamation and gastrointestinal symptoms, both present in 5 of the patients. Changes in the limbs, like erythema and/or edema, and the presence of lymph node enlargement $>1.5 \mathrm{~cm}$ were only present in 2 of the 7 children with incomplete KD. Analytical values at the time of KD diagnosis are shown in Table 2.

TABLE 1. General characteristics and clinical manifestations at the time of diagnosis

\begin{tabular}{|c|c|c|}
\hline & $\begin{array}{l}\text { Absolute } \\
\text { number }\end{array}$ & $\begin{array}{l}\text { Frequency } \\
(\%)\end{array}$ \\
\hline \multicolumn{3}{|l|}{ General characteristics } \\
\hline Sex (male); n (\%) & 19 & 61.3 \\
\hline Age in months old; median (IQR) & 18 & $12.2-40.3$ \\
\hline Younger than 5 years old; $\mathrm{n}(\%)$ & 27 & 87 \\
\hline Younger than 1 year old; n (\%) & 7 & 22.6 \\
\hline \multicolumn{3}{|l|}{ Fever $\geq 5$ days $*$} \\
\hline \multirow{4}{*}{\multicolumn{3}{|c|}{$\begin{array}{l}\text { Mean duration: } 7.71 \text { (5-25); SD: } 4 . \\
\text { Median: } 1 \text { (IQR: } 1-3) \\
\text { Mean maximum temperature: } \\
39.5^{\circ} \mathrm{C} \text {; SD: } 0.5\end{array}$}} \\
\hline & & \\
\hline & & \\
\hline & & \\
\hline Lymph node enlargement $(>1.5 \mathrm{~cm})^{*}$ & 17 & 58.7 \\
\hline Left & 5 & 29.4 \\
\hline Right & 10 & 58.8 \\
\hline Bilateral & 2 & 11.8 \\
\hline Rash $^{*}$ & 28 & 90.3 \\
\hline Maculopapular & 6 & 21.4 \\
\hline Scarlatiniform & 14 & 50 \\
\hline Urticarial & 2 & 7.1 \\
\hline \multicolumn{3}{|l|}{ Others (except petechiae or } \\
\hline & 6 & 21.4 \\
\hline \multicolumn{3}{|l|}{ Conjunctival hyperemia } \\
\hline without discharge* & 28 & 90.3 \\
\hline \multicolumn{3}{|l|}{ Lip/oral cavity involvement* } \\
\hline Redness/cracking of the lips & 26 & 100 \\
\hline Strawberry tongue & 18 & 78.3 \\
\hline Pharyngeal hyperemia & 24 & 77.4 \\
\hline Changes in limbs* & 26 & 89.7 \\
\hline \multirow{2}{*}{\multicolumn{3}{|c|}{$\begin{array}{l}\text { Acute phase: } \\
\text { Sub-acute phase: membranous }\end{array}$}} \\
\hline & & \\
\hline desquamation of fingertips & 26 & 89.7 \\
\hline Perineal desquamation & 5 & 26.3 \\
\hline Irritability & 20 & 69 \\
\hline \multicolumn{3}{|c|}{ Gastrointestinal involvement (vomiting, } \\
\hline jaundice, gallbladder hydrops) & 15 & 48.4 \\
\hline Joint involvement (arthralgias, arthrit & itis) 4 & 15.4 \\
\hline \multicolumn{3}{|l|}{ General status at the time of diagnosis } \\
\hline Adequate & 19 & 61.3 \\
\hline Fair or poor & 12 & 37.7 \\
\hline
\end{tabular}

* Diagnostic clinical criteria.

SD: standard deviation; IQR: interquartile range.

\section{Treatment}

Gammaglobulin was administered to all 31 patients $(100 \%)$ and, in three cases, medical records did not show whether they had received ASA. Eight patients had fever longer than 24 hours after receiving the first dose of gammaglobulin, therefore, a second dose was administered to 5 of them. In 6 cases, corticosteroids were administered during treatment, two of them had already received a second dose of gammaglobulin. The median time since the onset of symptoms and the administration of gammaglobulin treatment was 7 days (IQR: 7-10) in patients with incomplete KD, a median of 1 day more compared to the complete form of the disease (median: 6; IQR: 5-7.25).

\section{Complications}

CAD was detected in 5 patients. It was present in 4 of complete KD cases, and in 1 of incomplete KD. Of the 5 cases, one had two aneurysms with a diameter of $5 \mathrm{~mm}$ and $3.4 \mathrm{~mm}$ in the left coronary artery and a $6 \mathrm{~mm}$ aneurysm in the right coronary artery (risk IV). Another 2 patients had exclusive dilatation of the coronary arteries: one of them, of the right coronary artery of up to $3 \mathrm{~mm}$ (Z score: $+4.7)$ and the other patient of the right coronary artery $(3 \mathrm{~mm}$; Z score: +3.27$)$ and left coronary artery $(2.8 \mathrm{~mm}$; $Z$ score: +2.42$)$, both cases with a grade II risk. The two remaining patients had a grade III risk: in one of them, a dilatation of $2.7 \mathrm{~mm}$ of the left coronary artery was seen $(Z$ score: +3.25$)$ together with a 3.6-mm aneurysm in the anterior descending artery. The other child had a $4.7-\mathrm{mm}$ aneurysm in the left main

TABLE 2. Analytical data

\begin{tabular}{|c|c|c|}
\hline Laboratory data & Median & $\begin{array}{l}\text { Interquartile } \\
\text { range }\end{array}$ \\
\hline Total leukocytes (cells $/ \mathrm{mm}^{3}$ ) & 15800 & $11400-20800$ \\
\hline Neutrophils (cells $/ \mathrm{mm}^{3}$ ) & 10200 & $7900-14220$ \\
\hline Lymphocytes (cells $/ \mathrm{mm}^{3}$ ) & 3800 & $1700-5313$ \\
\hline Platelets (cells $/ \mathrm{mm}^{3}$ ) & 388000 & $274000-514000$ \\
\hline Hemoglobin (g/dL) & 11.3 & $10.4-11.8$ \\
\hline Albumin (g/dL) & 3.91 & $3.60-4.05$ \\
\hline Bilirubin (mg/dL) & 0.37 & $0.20-0.57$ \\
\hline GPT (U/L) & 29 & $16.8-123.3$ \\
\hline Sodium $(\mathrm{mEq} / \mathrm{L})$ & 137 & $135-138$ \\
\hline Potassium (mEq/L) & 4.3 & $4.13-5.05$ \\
\hline $\mathrm{CRP}(\mathrm{mg} / \mathrm{dL})$ & 9.73 & $7.11-16.10$ \\
\hline PCT (ng/ml) & 2.24 & $0.18-4.43$ \\
\hline ESR after 1 hour (mm) & 70 & 25-102 \\
\hline
\end{tabular}

Analytical data:

GPT (ALT): pyruvate-glutamate transaminase (alanine aminotransferase);CRP:C-reactive protein;PCT: procalcitonin; ESR: erythrocyte sedimentation rate. 
coronary artery and coronary ectasia of the left main coronary artery (left anterior descending: $3.3 \mathrm{~mm}$; left circumflex artery: $3.2 \mathrm{~mm}$ ). In 2 cases, the CAD was on the left side, while in the rest it was bilateral $(3 / 5)$. Likewise, other heart abnormalities were seen, e.g. pericardial effusion, which was present in 6 patients, of whom one had CAD.

Two patients had complete resolution of their CAD in the ultrasonographic follow-up at 6 weeks. Three patients had coronary changes persistence that did not disappear after one year follow-up.

\section{Risk factors for coronary involvement}

The results of the statistical analysis of clinical and analytical parameters studied in patients with and without CAD are shown in Table 3. Patients with CAD had a lower albuminemia (3.2 versus $3.99 \mathrm{mg} / \mathrm{dL}, p=0.002$ ) and had, for a cut-off point $<3.5 \mathrm{mg} / \mathrm{dL}$ of albuminemia, $100 \%$ sensitivity, $92.3 \%$ specificity, a positive predictive value (PPV) of $71.4 \%$ and a negative predictive value (NPV) of $100 \%$.

Patients with CAD had a higher CRP (median: $16.2 \mathrm{mg} / \mathrm{dL}$ versus $8.4 \mathrm{mg} / \mathrm{dL}, p=0.047$ ) and had, for a cut-off point of CRP $>12 \mathrm{mg} / \mathrm{dL}, 100 \%$ sensitivity, $69.2 \%$ specificity, a PPV of $38.5 \%$ and a NPV of $100 \%$.

The area under the curve (Receiver Operating Characteristic, ROC) for the diagnosis of CAD for CRP (Figure 1) and albumin (Figure 2) was 0.785 (95\% confidence interval [CI]: 0.63-0.94) and 0.938 (95\% CI: 0.85-1.00), respectively.
In the subset of patients with complete KD, the presence of gastrointestinal symptoms at the time of admission was related to CAD development $(p=0.02)$, as well as higher bilirubin levels with a median of $0.65 \mathrm{mg} / \mathrm{dL}$ (IQR: 0.57-0.98, $p=0.02$ ) versus a median of $0.3 \mathrm{mg} / \mathrm{dL}$ (IQR: 0.2-0.4) in patients without CAD.

No significant differences were found in the risk of CAD among the complete and incomplete forms of KD at the time of the diagnosis $(p=1.0)$, and a similar coronary injury prevalence was found between both groups $(1 / 7=14.3 \%$ in the incomplete form and $4 / 24=16.7 \%$ in the complete form).

\section{DISCUSSION}

Kawasaki disease etiology is unknown and there are no clinical or pathognomonic laboratory data for its diagnosis, therefore we depend on clinical criteria. However, there are children with incomplete KD that do not meet all criteria but who might have some coronary artery abnormalities. In different studies, the prevalence of the incomplete KD form ranges from $15 \%$ to $36.2 \%{ }^{5}$ of KD cases. The definitions posed by the different authors regarding the incomplete KD form conditions the prevalence of CAD found in the published studies. Sudo et al. ${ }^{5,8}$ indicated the presence of CAD in an echocardiography as a mandatory criterion for incomplete KD, so $100 \%$ of cases of incomplete KD had CAD. Manlhiot et al. 5,9 defined incomplete KD as fever for $\geq 5$ days and 2 or 3 of the standard criteria, disregarding echocardiographic findings. A similar CAD

TABLE 3. Results of the statistical analysis in patients with and without coronary artery involvement

\begin{tabular}{|c|c|c|c|}
\hline Laboratory clinical data & Without CAD $(n=26)$ Median (IQR) & With CAD (n= 5) Median (IQR)) & $p$-value \\
\hline Sex & $14 / 26$ male & $5 / 5$ male & 0.056 \\
\hline No. of days with fever & $6.0(5-7.5)$ & $7.0(6.5-14)$ & 0.172 \\
\hline Total leukocytes (cells/mm³) & $15250(11375-20125)$ & $19800(14950-22250)$ & 0.248 \\
\hline Total neutrophils (cells $/ \mathrm{mm}^{3}$ ) & $9990(6818-13700)$ & $14220(9050-15937)$ & 0.179 \\
\hline Total lymphocytes (cells $/ \mathrm{mm}^{3}$ ) & $4200(2150-5320)$ & $3400(1168-5620)$ & 0.747 \\
\hline Hemoglobin $(\mathrm{g} / \mathrm{dL})$ & $11.3(10.4-12.03)$ & $10.4(9.8-11.5)$ & 0.170 \\
\hline Platelets (cells $/ \mathrm{mm}^{3}$ ) & $411000(268250-522250)$ & $342000(233000-576000)$ & 0.707 \\
\hline Albumin $(\mathrm{g} / \mathrm{dL})$ & $3.99(3.78-4.10)$ & $3.23(2.42-3.29)$ & 0.002 \\
\hline Bilirubin (mg/dL) & $0.3(0.2-0.48)$ & $0.63(0.35-1.31)$ & 0.066 \\
\hline $\mathrm{GPT}(\mathrm{U} / \mathrm{L})$ & $22(14-123.5)$ & $75(29-109.5)$ & 0.231 \\
\hline $\mathrm{Na}(\mathrm{mEq} / \mathrm{L})$ & $137(135-138)$ & $134(131-138)$ & 0.189 \\
\hline $\mathrm{K}(\mathrm{mEq} / \mathrm{L})$ & $4.3(4.1-5)$ & $4.2(3.5-4.7)$ & 0.472 \\
\hline $\mathrm{CRP}(\mathrm{mg} / \mathrm{dL})$ & $8.42(5.85-15.07)$ & $16.2(12.17-19.0)$ & 0.047 \\
\hline PCT (ng/mL) & $1.73(0.12-3.52)$ & 4.05 (1.22-) & 0.355 \\
\hline
\end{tabular}

* Sex: data are shown in absolute value ratio.

CAD: coronary artery disease; IQR: interquartile range; GPT: pyruvate-glutamate transaminase; Na: sodium; K: potassium; CRP: C-reactive protein; PCT: procalcitonin. 
incidence was found in patients with complete $\mathrm{KD}$. In our study, CAD prevalence in incomplete and complete forms was similar $(14.3 \%$ and $16.7 \%, p=1.0$ ).

Echocardiography has allowed to detect a considerable number of children with KD and CAD who do not meet the standard criteria. ${ }^{10}$
Given that the presence of CAD is a very restrictive and specific criterion of incomplete $\mathrm{KD}$, the AHA has developed an algorithm with clinical and analytical criteria for the evaluation and treatment of patients in whom incomplete KD is suspected, which we have used as a gold standard in this study. As in other studies, ${ }^{11}$ we have found

FIGURE 1. ROC curve for the diagnosis of coronary involvement based on C-reactive protein

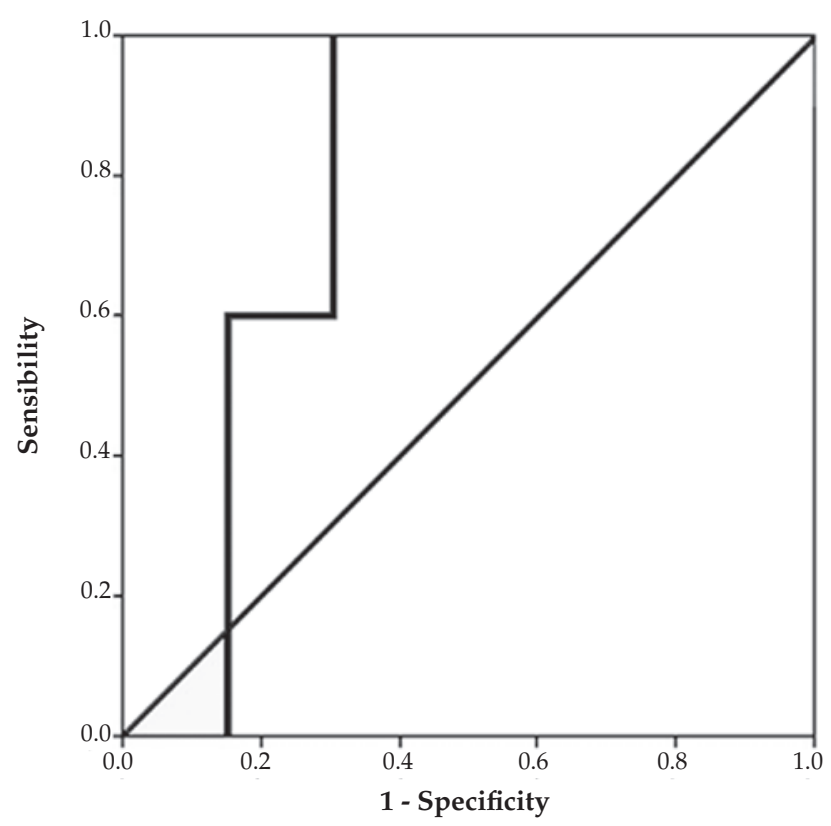

Area under the curve: $0.785 .95 \%$ CI $(0.627-0.958)$

FIGURE 2. ROC curve for the diagnosis of coronary involvement based on albumin

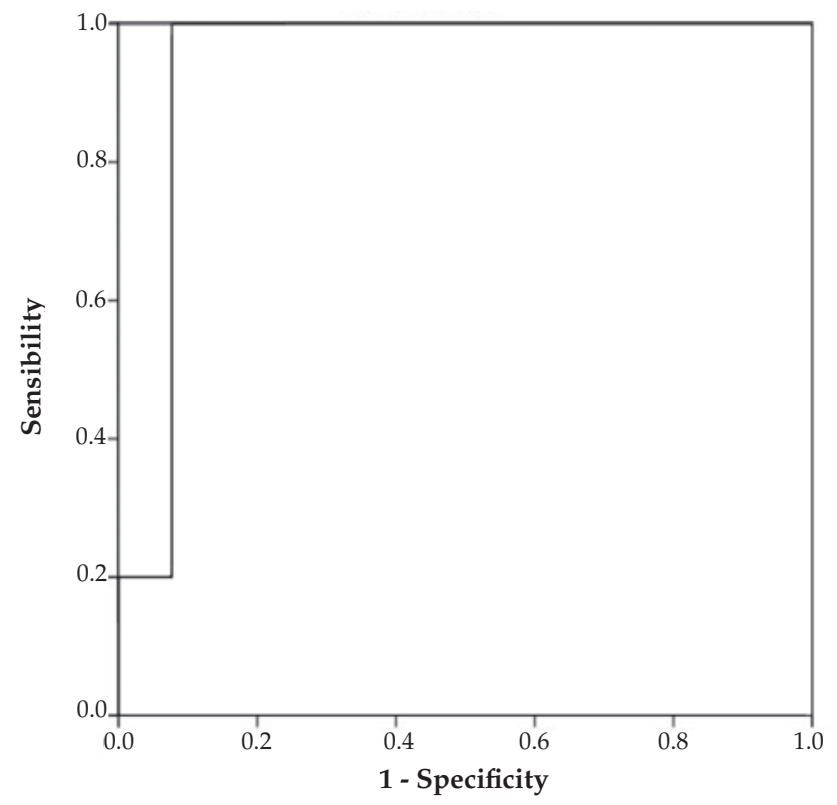

Area under the curve: $0.938 .95 \%$ CI $(0.850-1.000)$ 
a longer diagnostic delay in incomplete forms, which, in our case, has been 24 hours ( 7 versus 6 days) and that in incomplete forms could be related to a higher risk of developing CAD.

In our series, CRP and albumin levels have been related to the risk of developing CAD, as observed in other studies. ${ }^{12}$ In our study, albuminemia has shown an AUC of 0.938, indicating that there is an excellent correlation among the lower albumin values (cut-off point $<3.5 \mathrm{mg} / \mathrm{dL}$ ) and CAD risk. Other previously described risk factors for the development of CAD, like age under 1 year old or older than 9 years old, leukocytosis or hyponatremia were not confirmed in our study, probably because of the sample size limitation. N. Kitano et $\mathrm{al}^{13}{ }^{13}$ in a cohort of consecutive cases consisting of 1415 patients with KD, found that a rate of patients with CAD was significantly lower in the 11 to 48 month old age group $(2 \%, 17 / 859)$, compared to the group of children younger than 11 months old and older than 48 months old $(5.2 \%, 29 / 556)$, respectively $(p=0.001)$. These findings agree with our data because 3 out of the 5 patients with CAD were younger than 11 months old and one was older than 48 months old. The other patient was in the intermediate age range (12.1 months old).

Although the presence of gastrointestinal involvement (vomiting, diarrhea, abdominal pain, jaundice, gallbladder hydrops) and higher bilirubin levels in general are not factors related to the risk of CAD. Yi et al. ${ }^{14}$ studied such possible association and found that gallbladder hydrops and higher bilirubin levels were significantly related. In our study, in the complete form of $K D$, gastrointestinal symptoms and higher bilirubin levels were also significantly related to CAD. Similarly, K. H. Cho et al., ${ }^{15}$ retrospectively analyzed predictive factors of resistance to immunoglobulin therapy in 311 patients with complete and incomplete KD and found that, in patients with complete KD, total bilirubin levels $>0.56 \mathrm{mg} / \mathrm{dL}$ were significant predictors of resistance.

In our center, patients with KD are subjected to an echocardiography at the time of the diagnosis and in the course of 6-8 weeks. If they have CAD, they are done serially based on findings. If both are normal, follow-up is discontinued. However, in the study by V. Shah et $\mathrm{al}^{16}{ }^{16}$ in 92 patients with KD, markers of endothelial damage were examined 8.3 years after having had the disease, and they were compared to the control group. They found that in patients with KD, several of these markers persisted significantly increased both in patients with CAD as well as in those without $C A D$, which suggested the need of a long term follow-up of all patients who had had KD, even though they did not have CAD.

The main limitation of the study is its retrospective nature, with the inherent biases of this kind of studies. There is not a single definition of "incomplete KD" and this variability might make results differ from one to another study. We have used the definition proposed by the AHA in their worldwide known clinical guidelines. KD is defined by clinical diagnostic criteria, and its diagnosis is conditioned by several factors, e.g. the experience of the doctor taking care of the patient. In this study we tried to include only those patients whose medical records clearly reflected the defined clinical criteria, and the 4 doubtful cases were excluded.

To conclude, the risk of CAD in incomplete KD is similar to that in complete KD. In those patients who meet the defined criteria of incomplete KD, treatment with immunoglobulin should not be delayed so as to avoid a diagnostic delay that would eventually increase CAD risk. In our population, high CRP and low albumin levels and the presence of gastrointestinal involvement and higher bilirubin levels are related to a higher CAD risk.

\section{Acknowledgments}

To Jesús Ruiz Contreras, M.D., to Pablo Rojo Conejo, M.D., and to Enrique Salcedo Lobato, M.D., for their contribution to this study. To Miguel Ángel Granados Ruiz, M.D., and to Belén Toral Vázquez, M.D., of the Pediatric Cardiology Department in our center for their collaboration.

\section{REFERENCES}

1. Bou R. Enfermedad de Kawasaki. In: Asociación Española de Pediatría, ed. Protocolos de Reumatología. 2.a ed. Madrid: Asociación Española de Pediatría; 2014.Págs.117-29.

2. Sánchez-Manubens J, Bou R, Anton J. Diagnosis and classification of Kawasaki disease. J Autoimmun 2014;4849:113-7.

3. Caballero-Mora FJ, Alonso-Martín B, Tamariz-MartelMoreno A, Cano-FernándezJ, etal. Enfermedad deKawasaki en76 pacientes. Factores deriesgo deaparición deaneurismas coronarios. An Pediatr (Barc) 2011;74(4):232-8.

4. Martínez Ruiz M, del Castillo Martín F, Borque Andrés C, García Miguel MJ, et al. Incidencia y características clínicas de la enfermedad de Kawasaki. An Pediatr (Barc) 2003;59(4):323-7.

5. Yu JJ. Diagnosis of incomplete Kawasaki disease. Korean J Pediatr 2012;55(3):83-7.

6. Minich LL, Sleeper LA, Atz AM, McCrindle BW, et al. Delayed diagnosis of Kawasaki disease: what are the risk factors? Pediatrics 2007;120(6):e1434-40. 
7. Newburger JW, Takahashi M, Gerber MA, Gewitz MH, et al. Diagnosis, treatment, and long-term management of Kawasaki disease: a statement for health professionals from the Committee on Rheumatic Fever, Endocarditis and Kawasaki Disease, Council on Cardiovascular Disease in the Young, American Heart Association. Circulation 2004;110(17):2747-71.

8. Sudo D, Monobe Y, Yashiro M, Mieno MN, et al. Coronary artery lesions of incomplete Kawasaki disease: a nationwide survey in Japan. Eur J Pediatr 2012;171(4):651-6.

9. Manlhiot C, Christie E, McCrindle BW, Rosenberg H, et al. Complete and incomplete Kawasaki disease: two sides of the same coin. Eur J Pediatr 2012;171(4):657-62.

10. Witt MT, Minich LL, Bohnsack JF, Young PC. Kawasaki disease: more patients are being diagnosed who do not meet American Heart Association criteria. Pediatrics 1999;104(1):e10.

11. Chang FY, Hwang B, Chen SJ, Lee PC, et al. Characteristics of Kawasaki disease in infants younger than six months of age. Pediatr Infect Dis J 2006;25(3):241-4.
12. González Jiménez D, Alcántara Canabal L, Jiménez Treviño S, Ramos Polo E, et al. Enfermedad de Kawasaki. Experiencia en nuestro hospital. Bol Pediatr 2010;50(211):410.

13. Kitano N, Suzuki H, Takeuchi T, Suenaga $\mathrm{T}$, et al. Epidemiologic features and prognostic factors of coronary artery lesions associated with Kawasaki disease based on a 13-year cohort of consecutive cases identified by complete enumeration surveys in Wakayama, Japan. J Epidemiol 2014;24(5):427-34.

14. Yi DY, Kim JY, Choi EY, Choi JY, et al. Hepatobiliary risk factors for clinical outcome of Kawasaki disease in children. BMC Pediatr 2014;14:51.

15. Cho KH, Kang SJ. Clinically useful predictors of resistance to intravenous immunoglobulin and prognosis of coronary artery lesions in patient with incomplete Kawasaki disease. Korean Circ J 2014;44(5):328-35.

16. Shah V, Christov G, Mukasa T, Brogan KS, et al. Cardiovascular status after Kawasaki disease in the UK. eart 2015;101(20):1646-55. 